\section{Variation in Flower Senescence and Ethylene Biosynthesis among Carnations}

\author{
Amanda S. Brandt and William R. Woodson ${ }^{1}$ \\ Department of Horticulture, Purdue University, West Lafayette, IN 47907 \\ Additional index words. ACC, Dianthus caryophyllus, ethylene-forming enzyme
}

\begin{abstract}
We have investigated the patterns of ethylene biosynthesis in carnation (Dianthus caryophyllus L.) genotypes that exhibit extended vase life in comparison to flowers of White Sim'. 'White Sim' flowers exhibited typical symptoms of senescence, including petal in-rolling and rapid wilting, beginning 5 days after harvest. In contrast, the other genotypes studied did not show petal in-rolling or rapid wilting associated with petal senescence. The first visible symptom of senescence in these flowers was necrosis of the petal tips, and it occurred from 3 to 7 days after the initial symptoms of senescence were seen in 'White Sim' flowers. In all cases, the extended-vase-life genotypes did not exhibit the dramatic increase in ethylene production that typically accompanies petal senescence in carnation. This appeared to be the result of limited accumulation of ACC. In addition, flowers of these genotypes had limited capacity to convert ACC to ethylene. Therefore, we conclude that the low level of ethylene produced by these flowers during postharvest aging is the result of low activities of both ACC synthase and the ethylene-forming enzyme. Treatment of 'White Sim' flowers at anthesis with $1.0 \mu \mathrm{l}$ ethylene/liter resulted in the induction of increased ethylene biosynthesis and premature petal senescence. The extended-vase-life genotypes exhibited varying responses to ethylene treatment. One genotype $(87-37 \mathrm{G}-2)$ produced elevated ethylene and senesced prematurely, as did flowers of 'White Sim'. A second genotype (82-1) was induced to senesce by ethylene treatment but did not produce increased ethylene. A third genotype (799) was unaffected by ethylene treatment. The results of this study suggest these extended-vase-life genotypes are representative of genetic differences in the capacity to synthesize and respond to ethylene. Chemical name used: 1-aminocyclopropane-1-carboxylic acid (ACC).
\end{abstract}

Flower senescence is a highly coordinated, developmentally regulated process requiring active gene expression and protein synthesis (Borochov and Woodson, 1989). In carnation, the phytohormone ethylene plays an important role in the initiation and regulation of the biochemical processes that accompany petal senescence, including activation of senescence-related gene expression (Lawton et al., 1990). Treatment of flowers with inhibitors of ethylene synthesis (Bufler et al., 1980) or ethylene action (Bufler et al., 1980; Veen, 1979; Wang and Woodson, 1989) prevents typical petal senescence. Further, treatment of presenescent flowers with ethylene induces premature petal senescence (Nichols, 1968). The onset of petal senescence in carnations is accompanied by a dramatic rise in ethylene production $(\mathrm{Ni}-$

Received for publication 16 Dec. 1991. Accepted for publication 3 Apr. 1992. Publication no. 13,254 of the Purdue Univ. Agricultural Experiment Station. This research was supported by a grant from the United States-Israel Binational Agricultural Research and Development Fund grand no. US1876-90R. We are grateful to Roger Ulinger (deceased) for bringing these carnations to our attention and providing the plant material used in these studies, The cost of publishing this paper was defrayed in part by the payment of page charges. Under postal regulations, this paper therefore must be hereby marked advertisement solely to indicate this fact.

'To whom correspondence should be addressed. chols, 1966). This increase is the result of increases in activities of both ACC synthase and the ethylene-forming enzyme (EFE), which convert $S$-adenosylmethionine (SAM) to ACC and oxidize ACC to ethylene, respectively (Park et al., 1992; Woodson et al., 1992). In carnations, the capacity to perceive and synthesize ethylene is clearly central to the regulation of petal senescence. The identification of genotypic variation in either the response to ethylene or ethylene production in carnation could lead to a more focused breeding effort in the genetic improvement of postharvest longevity of these flowers. Indeed, several commercial cultivars have been described that exhibit extended vase life (Serrano et al., 1991; Wu et al., 1991a). In all cases, the long vase lives of these cultivars are associated with the absence, reduction, or delay of ethylene production that serves to initiate and regulate programmed cell death. In addition to re-

Table 1. Vase life and senescence patterns of carnation genotypes.

\begin{tabular}{lcc}
\hline \hline Genotype & \multicolumn{1}{c}{$\begin{array}{c}\text { Vase life } \\
\text { (days) }^{2}\end{array}$} & $\begin{array}{c}\text { Senescence } \\
\text { pattern }^{y}\end{array}$ \\
\hline White Sim & $5.3 \pm 0.9$ & $\mathrm{I}, \mathrm{W}$ \\
$87-37 \mathrm{G}-2$ & $8.1 \pm 1.3$ & $\mathrm{~N}$ \\
$81-2$ & $10.9 \pm 2.1$ & $\mathrm{~N}$ \\
799 & $11.2 \pm 1.8$ & $\mathbf{N}$ \\
\hline
\end{tabular}

${ }^{2}$ Values are the mean of 10 flowers \pm SE.

${ }^{y}$ Petal in-rolling (I), rapid petal wilting (W), and petal necrosis $(\mathrm{N})$. duced ethylene biosynthesis, the long-lasting cultivar Chinera was recently found to be less sensitive to ethylene than other carnation flowers (Wu et al., 1991b). Clearly, genetic mutations affecting ethylene synthesis or responsiveness are valuable tools in the study of flower senescence. In this paper we describe the ethylene biosynthesis, ethylene responsiveness, and senescence patterns of three carnation genotypes that exhibit extended vase life in comparison to 'White Sim' flowers.

Carnations were obtained as rooted cuttings from either Yoder Brothers ("White Sim') or R. Ulinger of the Univ. of $\mathrm{Ne}$ braska. These represented selections that Ulinger had identified as having improved vase life and limited "sleepiness" symptoms (petal in-rolling). Plants were grown in greenhouses using standard commercial practices (Woodson, 1987). Flowers were harvested when petals were reflexed to form 90 " angles with respect to the axis of the calyx. Stems were recut to a length of 10 $\mathrm{cm}$, placed in distilled water, and kept in the laboratory at 20C. Flowers were evaluated for symptoms of senescence, including inrolling of the petals (Nichols, 1968), irreversible wilting, and necrosis. Ethylene production was measured daily by enclosing flowers in 1-liter gas-tight containers for 0.5 $\mathrm{h}$, after which the headspace gas was sampled and ethylene concentration determined

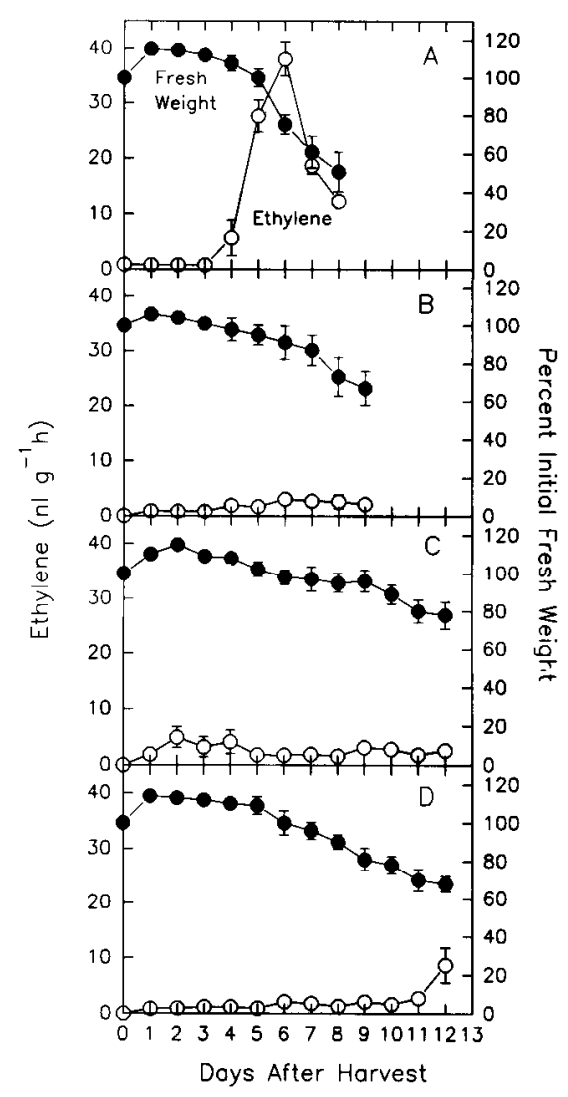

Fig. 1. Ethylene production ( $\mathrm{O}$ ) and change in fresh weight ( ) during the postharvest vase life of carnation flowers. Genotypes used were 'White Sim' (A), 87-37G-2 (B), 81-2 (C), and 799 (D). Values are the mean of 10 flowers. SE of the mean is shown when larger than the symbol. 


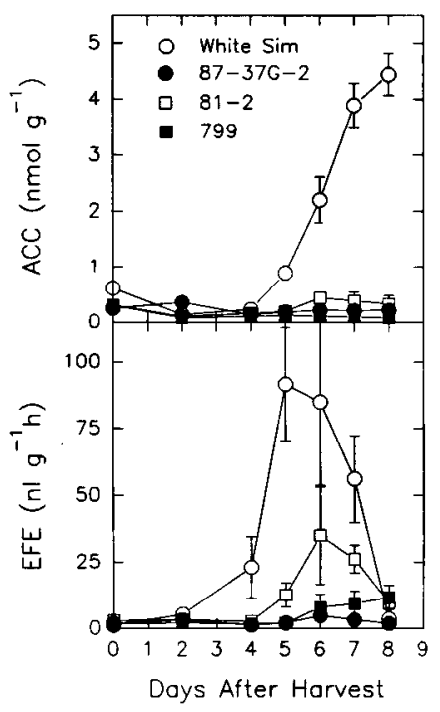

Fig. 2. Changes in ACC content and ethyleneforming enzyme (EFE) activity during the postharvest vase life of carnation flower petals. 'Values are the mean of five samples. SE of the mean is shown when larger than the symbol

by gas chromatography as described by Woodson (1987). ACC content and EFE activity of outer whorl petals were determined according to Wang and Woodson (1989). For treatment with ethylene, flowers were enclosed in 24-liter gas-tight chambers through which a mixture of ethylene in air was passed at a rate of $60 \mathrm{ml}-\mathrm{min}^{-1}$. The concentration of ethylene in the chamber was verified by analysis of ethylene concentration in the influx and efflux air.

All three carnation genotypes furnished by Ulinger exhibited significant extension of flower vase life in comparison to 'White Sim' carnations (Table 1). The vase life of genotype 799 was more than twice that of 'White Sim'. Senescence of 'White Sim' carnations was associated with typical symptoms, including petal in-rolling and rapid wilting beginning » 5 days after harvest. In contrast, the senescence of the extended-vase-life genotypes was not associated with petal inrolling or rapid wilting. Instead, the first symptoms of petal senescence in these genotypes were drying and necrosis of the petal tips, which slowly spread to the remaining petal portions. The in-rolling and wilting of 'White Sim' petals has been shown to be a response to the increase in ethylene production associated with petal senescence (Borochov and Woodson, 1989; Nichols, 1966, 1968). Senescence symptoms in the extended-vase-life genotypes were typical of those in 'White Sim' following treatment with the ethylene action inhibitor silver thiosulfate (Bufler et al., 1980; Veen, 1979). Therefore, we determined the rate of ethylene production by carnation flowers at various stages after harvest and related this to symptoms of senescence, including water loss, as measured by flower fresh weight.

'White Sim' began producing a detectable increase in ethylene production beginning 4 days after harvest and peaking at 6 days (Fig. 1A). This increase in ethylene production was

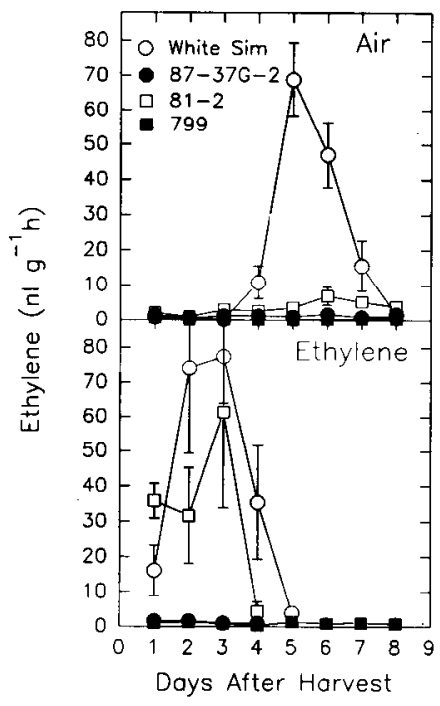

Fig. 3. Ethylene production following treatment with $1.0 \mu$ ethylene/liter or air for $12 \mathrm{~h}$. Flowers were harvested at anthesis and treated for $12 \mathrm{~h}$. Values are the mean of 10 flowers. SE of the mean is shown when larger than the symbol.

associated with a dramatic loss of fresh weight and rapid petal wilting. In contrast, none of the other genotypes examined exhibited this typical "climacteric" increase in ethylene production (Fig. 1B-D). Genotype 799 showed a significant increase in ethylene production 12 days after harvest, at which time these flowers were severely wilted and considered senescent. Therefore, this ethylene likely represents a stress response. The extended-vase-life carnations all showed significant loss of fresh weight beginning 2 to 3 days after harvest (Fig. 1B-D). However, in contrast to 'White Sim' (Fig. 1A), this loss of weight was gradual. These results suggest that the significant improvement in flower vase life exhibited by these genotypes is a result of low rates of ethylene production.

In an attempt to determine the biochemical reason for the limited production of ethylene by these carnation flowers, we analyzed petal ACC content and capacity to convert ACC to ethylene (EFE activity). 'White Sim' petals accumulated increasing amounts of ACC concomitant with the onset of ethylene production and visible symptoms of senescence (Fig. 2). In contrast, the content of $\mathrm{ACC}$ remained low $\left(<1.0 \mathrm{nmol} \cdot \mathrm{g}^{-1}\right)$ in the petals of all three of the extended-vase-life genotypes following harvest of flowers. The activity of EFE was initially low in 'White Sim' petals but began to increase 4 days after harvest, reaching a maximum activity 5 days after harvest and then declining (Fig. 2). Activity of EFE remained low in petals of 87 37G-2 and 799 flowers after harvest but showed a transient increase beginning 5 days after harvest in petals of 81-2 flowers. These results show that the limited production of ethylene in all three of these genotypes is the result of low levels of ACC, likely the result of low activity of ACC synthase. In addition, low activities of the EFE limit ethylene production in 87-37G-2 and 799.
The increase in ethylene associated with petal senescence in climacteric carnations like 'White Sim' is the result of autocatalytic ethylene, where ethylene promotes its own synthesis (Borochov and Woodson, 1989). The effect of ethylene on ethylene production has been shown to occur at the level of both ACC synthase and EFE (Park et al., 1992; Wang and Woodson, 1989; Woodson et al., 1992). Treatment of these climacteric-like flowers with ethylene results in the induction of autocatalytic ethylene production and premature petal senescence. A possible explanation for the variant behavior of these extended-vase-life carnation genotypes is that they are not capable of responding to ethylene. Recently, several genetic mutations have been characterized in Arabidopsis that impair the capacity to perceive and respond to ethylene (Bleecker et al., 1988; Guzman and Ecker, 1990). To examine this possibility we exposed freshly harvested carnation flowers to $1.0 \mu \mathrm{l}$ ethylene/liter for $12 \mathrm{~h}$ and determined the effects of this treatment on ethylene production and flower senescence. Treatment of 'White Sim' with ethylene resulted in increased ethylene production and visible symptoms of petal senescence (inrolling and wilting) detectable the day after ethylene exposure (Fig. 3). A similar response, i.e., increased ethylene and petal inrolling, occurred in genotype 81-2. Flowers of $87-37 \mathrm{G}-2$ responded to ethylene as evidenced by petal in-rolling and rapid irreversible wilting (data not shown). These flowers, like those of 'White Sim', were considered completely senescent 3 days after harvest (data not shown). In contrast to flowers of 'White Sim', 87-37G-2, and 81-2, flowers of 799 showed no obvious effects of the ethylene treatment. These flowers did not exhibit an increase in ethylene production and remained attractive 8 days after harvest, at which time the experiment was terminated.

These results indicate that the three extended-vase-life genotypes likely represent different genetic mutations that affect the postharvest longevity of their flowers. Genotype 799 was impaired in its ability to respond to ethylene by increased ethylene production or premature petal senescence. A second genotype, 87-37G-2, appears to represent a mutation affecting the synthesis of ethylene but not ethylene responsiveness. The third genotype examined was capable of synthesizing ethylene in response to ethylene treatment but failed to produce ethylene during normal aging. This pattern is analogous to the recently described behavior of nonclimacteric carnation 'Sandra' (Wu et al., 1991a, 1991b), which failed to produce elevated ethylene during aging but responded to exogenous ethylene by increased ethylene synthesis and premature senescence. These genotypes may be useful in breeding programs where improvement of carnation postharvest longevity is sought. In addition, genotypes that exhibit variation in ethylene synthesis and response will be valuable tools in studies on the physiology and biochemistry of senescence, particularly as related to the role of ethylene in programmed cell death. 


\section{Literature Cited}

Bleecker, A.B., M.A. Estelle, C. Somerville, and H. Kende. 1988. Insensitivitv to ethylene conferred by a dominant mutation in Arabodopsis thaliana. Science 241:1086-1089.

Borochov, A. and W.R. Woodson. 1989. Physiology and biochemistry of flower petal senescence. Hort. Rev. 11:15-43.

Bufler, G., Y. Mor, M.S. Reid, and S.F. Yang. 1980. Changes in 1-aminocyclopropane-1-carboxylic acid-content of cut carnation flowers in relation to their senescence. Planta 150:439442.

Guzman. P. and J.R. Ecker. 1990. Exploiting the triple response of Arabidopsis to identify ethvlene-regulated mutants. Plant Cell 2:513-523.

Lawton, K.A., K.G. Raghothama, P.B. Goldsbrough, and W.R. Woodson. 1990. Regulation of senescence-related gene expression in car- nation flower petals by ethylene. Plant Physiol. 93:1370-1375.

Nichols, R. 1966. Ethylene production during senescence of flowers. J. Hort. Sci. 41:279-290.

Nichols, R. 1968. The response of carnations (Dianthus caryopyllus) to ethylene. J. Hort. Sci. 43:335-349.

Park, K.Y., A. Drory, and W.R. Woodson. 1992. Molecular cloning of an 1-aminocyclopropane1-carboxylate synthase from senescing carnation flower petals. Plant Mol. Biol. 18:377386.

Serrano, M., F. Romojaro, J.L. Casas, and M. Acosta. 1991. Ethylene and polyamine metabolism in climacteric and nonclimacteric carnation flowers. HortScience 26:894-896.

Veen, H. 1979. Effects of silver on ethylene synthesis and action in cut carnations. Planta 145:467-470.

Wang, H. and W.R. Woodson. 1989. Reversible inhibition of ethylene action and interruption of petal senescence in carnation flowers by norbornadiene. Plant Physiol. 89:434-438.

Woodson, W.R. 1987. Changes in protein patterns and mRNA populations during senescence of carnation petals. Physiol. Plant. 71:495-502

Woodson, W.R., K.Y. Park, A. Drory, P.B. Larsen, and H. Wang. 1992. Expression of ethylene biosynthetic pathwav transcripts in senescing carnation flowers. Plant Physioi. 99:526-532,

Wu. M.J.. W.G. van Doom. and M.S. Reid 1991a. Variation in the senescence of carnation (Dianthus caryophyllus L.) cultivars. I. Comparison of flower life, respiration and ethylene biosynthesis. Scientia Hort. 48:99-107.

Wu, M.J., L. Zacarias, and M.S. Reid. 1991b. Variation in the senescence of carnation (Dianthus caryophyllus L.) cultivars. II. Comparison of sensitivity to exogenous ethylene and of ethylene binding. Scientia Hort. 48:109-116. 